\title{
Unpublished Mathematical Text from Tell IBZIKH in the Iraqi Museum
}

\author{
Asst.Prof.Dr.Salim.y.Aljuboori \\ Univ. of Mosul, Archeology college \\ Dep. Inscription and Ancient Iraq's languages.
}

The Babylonians introduced the greatest of civilizational achievements in the history of mankind in different branches of knowledge, especially mathematics, because it is the language of sciences and the basis upon which the other sciences are built, such as astronomy, physics, chemistry, geometry and etc....Actually, the achievement, that took place in Mesopotamia are regarded as the cornerstone of all inventions that appeared in different adjacent countries and in later different periods. Also, the remains and the information that came down to us underline the greatness of this people and the originality of this civilization $^{(1)}$. Because of this development, we preferred to focus on a type of mathematics which is seen as one of the natural consequences of the economic and intellectual development in Mesopotamia. Despite its initial steps which are considered experimental knowledge, it Later took important steps towards discovering a number of scientific facts that resulted from the abstract theoretical meditations ${ }^{(\Upsilon)}$. Among these achievements is our present research entitled "Unpublished Mathematical Text from Tell Al-IBZIKH in the Iraqi Museum" It discusses the square roots for numbers T ${ }_{-} \leqslant$T. It is probable that the text may continue to other multiplications of number $\varepsilon$ - and other numbers. But we believe that the obverse of the tablet ended with number $\leqslant r$ through the right edge of the tablet ${ }^{(\tau)}$ which seems to us that the text ended her. As regards the reverse side of the tablet nothing is written on it. It came from the excavations made by the Iraqi mission specifically in the second season of $r . r$ in ZABALUM whose remains are currently known by tell IBZIKH, which lies in THIQAR. by $\mathrm{r}^{q} \cdot \mathrm{km}$ south of Baghdad ${ }^{(\xi)}$ It was found in this first western point in square $\mathrm{I}$ with depth of $19 . \mathrm{cm}$. Its dimensions were $0.7 \mathrm{~cm} x \leqslant . \wedge \mathrm{cm} x 1 . \wedge \mathrm{cm}$. It is presently preserved in the Iraqi museum under number $19 \leqslant \uparrow \wedge 9$.

\section{How to Read Square Roots?}

The Babylonian writer in mathematics depended on numerous way in writing, counting and tabulating numbers by using mathematical rules which he reached across a long period of time. We find that he organized number- related tables through writing the right numbers in the first column on the left. Then he leaves a space between the right number and the following number as a reference that this space is like a decimal point for the right number. After that, he writes the cuneiform mark ( $)^{\left.()^{\circ}\right)}$ with reading (e), which means the number itself. the required number comes after this mark, followed by the Sumerian mathematical term BA.SI, or ÍB. SI Its counterpart in Akkadian is (bâsum) which means the square root ${ }^{(\urcorner)}$ of the number. Thus, the ancient Iraqis left behind them tables with square roots as follows: ${ }^{(\vee)}$

\begin{tabular}{|c|c|c|}
\hline 1 & square roots of & 1 \\
\hline$r$ & square roots of & $\varepsilon$ \\
\hline$r$ & square roots of & $q$ \\
\hline
\end{tabular}


Perhaps this text might have divided for the economy of effort exerted by the researcher in field of mathematics. In addition, the ancient Babylonian writer, through his experience discovered the multiplication of the number by itself, there by extracting the square root, Therefore, these tables were like a dictionary consulted by the writer. It is obvious that the writer used the sixty system when finding the square result for knowing the root of any number. An example is $r$

$1 \wedge * \eta \cdot+9=1 \cdot 19$

It is the square of the number; the same result of the number $r$ r $* r=1 \cdot 19$.

The Akkadian Translation:

r e 11.9 ÍB.SI^

namely it is the square root of $r \mathrm{r}=1 \wedge .9$.

It seems that the writer made many attempts until he arrived at a precise mathematical method which is the multiplication of the number by the biggest numerical value which is sixty because the arithmetic system depended on the sixty system, for example, the multiplication of $1 \wedge * \uparrow \cdot$ gives the result $1 \cdot \wedge \cdot$, and it is an approximate number to the result of its root if we multiply $r$ r $r$ which equals $1 . \wedge 9$ which is too near from the previous result. Hence, he added 9 to get the number $1 \wedge .9$ which is the square root of $r \mathrm{r}$, we find him continues extracting the roots of numbers which follow $T^{\top}$ until he comes to $r v$ with successive results. For example, $r$ had a square root which is $17.1, r r$ had $I V . \varepsilon$ and $r V$ had $r r$. $₹ \uparrow$, but when he reaches $r \wedge$, we did not find this succession in the results rather, he moved to $r \leqslant \varepsilon$ the reason is attributed to the fact that $r$, if multiplied by $r \cdot$, gives a different results from the requested number which is $1 \leqslant \varepsilon \varepsilon$. this number is the result of multiplying $r \wedge$ by itself. the result is obtained by multiplying $r \leq$ by $\uparrow$. then he added $\leqslant$ to give the same result. By this concord this mathematician arrived at scientific steps with positive results which now served the Iraqi society. the following is the translation of the cuneiform text: 
$\operatorname{IM}(19 \leq 49 \wedge)$

Obv.

Analysis

\begin{tabular}{|c|c|c|}
\hline 1) 17.1 & $e^{r l}$ & $\overline{\mathrm{IB}} . \mathrm{SI}_{\wedge}$ \\
\hline$I V . \varepsilon$ & e rr & ÍB.SI \\
\hline 11.9 & err & $\mathrm{IIB}_{\mathrm{I}} \mathrm{SI}_{\curlywedge}$ \\
\hline 19.17 & $e^{T} \varepsilon$ & ÍB.SI \\
\hline o) $r \cdot r_{0}$ & e To & $\mathrm{IIB}^{\mathrm{I}} \mathrm{SI}_{\curlywedge}$ \\
\hline ד. Tו & e rt & ÍB.SI^ \\
\hline YY. $\leqslant q$ & $e^{r v}$ & ÍB.SI \\
\hline$T \varepsilon . \varepsilon$ & erk & $\mathrm{IIB}^{\mathrm{I}} \mathrm{SI}_{\curlywedge}$ \\
\hline YO. YI & $e^{r q}$ & ÍB.SI^ \\
\hline 1•) $Y[\Upsilon . \varepsilon \cdot]$ & e $\varepsilon$ & $\mathrm{IIB}^{\mathrm{I}} \mathrm{SI}_{\curlywedge}$ \\
\hline$[Y \wedge .1]$ & $e \leqslant 1$ & ÍB.SI^ \\
\hline$[Y q, Y \leqslant]$ & $e \leqslant r$ & ÍB.SI \\
\hline
\end{tabular}

\begin{tabular}{|c|c|c|}
\hline 1) 17.1 & $971=$ & $\Gamma T^{r}$ \\
\hline IV.z & $1 \cdot r \leq=$ & $\overline{r r}$ \\
\hline 11.9 & $1 \cdot 19=$ & Tr \\
\hline 19.17 & $1107=$ & $r \varepsilon^{r}$ \\
\hline o) $r \cdot r_{0}$ & IYYO = & ror \\
\hline YI.rT & $1 Y 97=$ & $r \tau^{r}$ \\
\hline YY. $\varepsilon q$ & $11479=$ & $r V^{r}$ \\
\hline$r \leqslant . \leqslant$ & $1 \leq \varepsilon \leq=$ & $r \Lambda^{r}$ \\
\hline YO.YI & $10 Y 1=$ & $r q^{r}$ \\
\hline 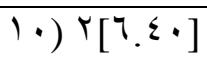 & $17 \ldots=$ & $\varepsilon \cdot r$ \\
\hline$[Y \wedge .1]$ & $|7 \lambda|=$ & $\varepsilon I^{r}$ \\
\hline$[Y q . Y \leqslant]$ & IVTE = & $\varepsilon r^{r}$ \\
\hline
\end{tabular}

the text size $(0.7 * \varepsilon . \wedge * 1 . \wedge)$
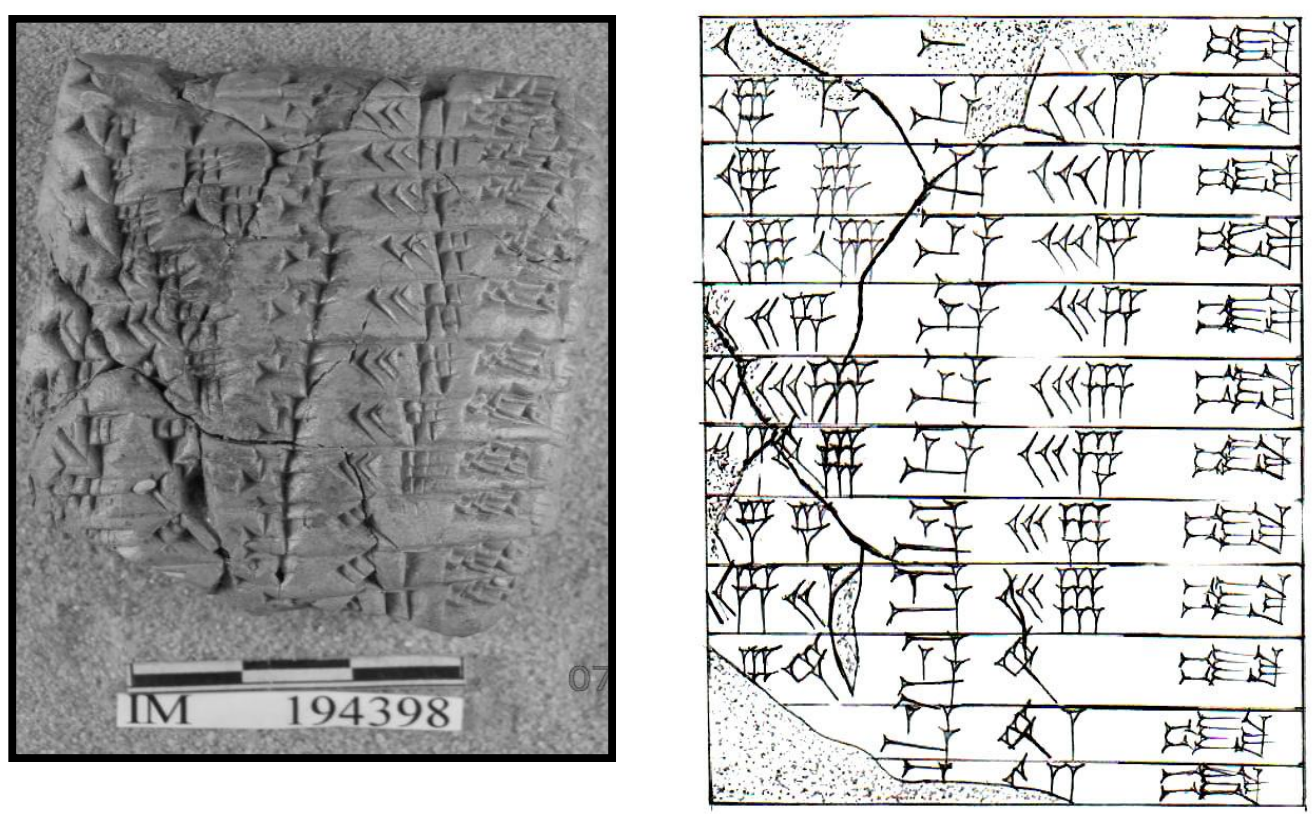


\section{References}

1. Alghurabi, Saleem Ismael, "Mathematics in Mesopotamia" (the Babylonian period). researches of the fifth regional symposium of the history of Arab sciences, (in Arabic), vol. ।, U of Baghdad, $19 \wedge 9$, p. $\diamond \wedge$. .

r. Alrawi, Farooq Nasir, "the landmarks and the ancient Iraqi exact sciences in civilize-ation" Iraq in the procession of civilization, (in Arabic), vol. ।, Baghdad, । १^^, p. $\uparrow \wedge$ ।

r. see the illustration ,p. $\bullet$.

£. Alsabeehawi, Haidr Farhan, "the archeological excavations in Ibzikh the first and the second seasons

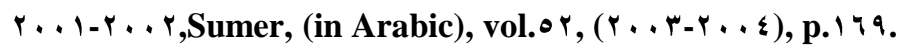

๑. Labat .R,Manuel D’Épigraphie Akkadienne, Paris $19 \vee 7$, p. $1 \leqslant 1$.

ฯ. Black.J.; George. A.; postagate. N, A concise dictionary Akkadian, $r^{\text {nd }}$, wiesband, r. . ,p.. .

৩. Alrawi, Farooq Nasir, op.cit, p. $\uparrow \wedge \vee$. 